Article

\title{
An Augmented Reality Facility to Run Hybrid Physical-Numerical Flood Models
}

\author{
Jerónimo Puertas ${ }^{1}$, Luis Hernández-Ibáñez ${ }^{2} \mathbb{D}$, Luis Cea ${ }^{1}$, Manuel Regueiro-Picallo ${ }^{3, * \mathbb{D}}$, \\ Viviana Barneche-Naya ${ }^{2}$ and Francisco-Alberto Varela-García ${ }^{2}$ (D) \\ 1 Water and Environmental Engineering Group (GEAMA), Department of Civil Engineering, Universidade da \\ Coruña, 15071 Elviña, A Coruña, Spain; jeronimo.puertas@udc.es (J.P.); luis.cea@udc.es (L.C.) \\ 2 Advanced Visualization and Cartography Group (VAC), Centre for Technological Innovation in \\ Construction and Civil Engineering (CITEEC), Universidade da Coruña, 15071 Elviña, A Coruña, Spain; \\ luis.hernandez@udc.es (L.H.-I.); viviana.barneche@udc.es (V.B.-N.); alberto.varela@udc.es (F.-A.V.-G.) \\ 3 Water and Environmental Engineering Group (GEAMA), Centre for Technological Innovation in \\ Construction and Civil Engineering (CITEEC), Universidade da Coruña, 15071 Elviña, A Coruña, Spain \\ * Correspondence: manuel.regueiro1@udc.es; Tel.: +34-881-01-5178
}

Received: 29 September 2020; Accepted: 21 November 2020; Published: 23 November 2020

\begin{abstract}
This article presents a novel installation for the development of hybrid physical-numerical flood models in an augmented reality environment. This installation extends the concept introduced by the well-known Augmented Reality-SandBox (AR-Sandbox) module, which presents a more educational, and less research-based and professional application. It consists of a physical scale topography built in a sandbox into which other elements (such as buildings, roads or dikes) can be incorporated. A scanner generates, in real time, a Digital Terrain Model (DTM) from the sandbox topography, which serves as a basis for the simulation of overland flow using professional hydraulic software (Iber+). The hydraulic and hydrological parameters (surface roughness, inlet discharges, boundary conditions) are entered with a simple Graphical User Interface (GUI) developed specifically for this project, as indeed was the entire system that allows the visualization of the simulation results. This allows us to obtain quantitative results of flood extension and magnitude, which are represented directly over the physical topography, yielding a realistic visual effect. This installation is conceived for both educational and professional uses. An example of its use is presented, through which its accuracy can be appreciated, and which also illustrates its potential.
\end{abstract}

Keywords: physical modelling; numerical modelling; floods; fluvial hydraulics; innovative facilities; augmented reality

\section{Introduction}

Traditionally there have been two methodologies for the analysis of hydraulic phenomena: numerical methods and physical models. Physical hydraulic modelling provides closeness to the problem and a visualization of the physical environment that is difficult to achieve with numerical models. [1]. Observing a problem in three dimensions, perceiving how water flows over a floodplain, and proposing solutions to avoid this, can be done in a much more intuitive way with a physical model than in a numerical model [2].

On the other hand, numerical models have evolved considerably in recent years. Most of the problems that can be studied by means of physical models can now also be approached using numerical models. In particular, within the field of flood risk management, the use of physical models is becoming less frequent, since nowadays numerical models provide reliable and accurate solutions $[3,4]$. 
In addition, physical models require large and expensive installations $[5,6]$, which sometimes makes them very uncompetitive.

Thus, when faced with a conventional hydraulic problem such as the evaluation of river inundations and the design of defensive barriers or controlled flooding areas, the current trend is towards numerical modeling, although this entails a certain distance from physical reality and does not encourage the development of new creative solutions arising from the three-dimensional observation of the problems and from immersion in the terrain.

3D visualization technologies that allow for virtual immersion are currently available [7]. Technical staff feel comfortable working in an immersive way in these environments, and thus this line of work should be encouraged. Since the late 1990s, installations for the interactive display of topographic models have been available for educational purposes, such as TerraVision [8] and SANTI [9]. These are based on the simulation in real time of topographic or cartographic models projected onto a surface (not necessarily a screen) or globes [10]. The use of these installations is usually museum-based, and therefore they tend to be manipulated by some system of natural interaction, without visible devices. Examples in museums and exhibitions around the world can be found, simulating everything from urban growth to nature trails and hurricane behavior. There are also examples of technical use, some of which were developed by the authors [11]. When video mapping techniques are applied to a real object in installations of this type, the result is to augment reality with projected digital information. If, in addition, the geometry is mutable, its shape must be recognized at all times through some kind of sensor. Several initiatives have been developed in this direction within the field of topographic representation, among which MIT's SandScape [12], iSandBox [13], Projection augmented relief models (PARM) [14] and the popular ARSandbox [15,16] stand out.

On the other hand, a collaborative approach to flood problems offers various advantages. These include being able to discuss and debate technical solutions in a group while observing the flow in a physical model; testing alternatives in real time by means of small changes in the physical reality, carried out quickly; and seeing how the water varies its circulation, for example, by opening a diversion or by placing a barrier to the flow to protect an urban area. Such an approach brings the issues closer to all those involved, be they technical personnel or others linked to the project without technical training. This latter group, they undoubtedly visualize solutions better in a physical environment than on a screen or with virtual reality glasses.

In addition, physical models have considerable value in the realm of teaching. Not everyone is able to visualize three-dimensional flooded areas drawn on a screen or on a map. At the same time, the training of technicians should include contact with physical reality. Obviously, it is optimal that this physical reality be as real as possible, and it is better to visit a real infrastructure than a scale model. However, a scale model allows us to vary the operating conditions and to test situations that could never be created in the real world, and this is undoubtedly of great educational value. Such physical models are also valuable as a means of disseminating and extending scientific-technical knowledge and interest. In this way, high school students can find hydraulic laboratories attractive, an effective way of encouraging them to consider scientific-technical careers.

Hydraulic laboratories and physical models are expensive and thus it is not always economically feasible to use them. Using numerical models is a more economically efficient approach that might be applied in cases in which the numerical solution is reliable and accurate. This article proposes a hybrid solution, based on the development of a small-scale physical model, the calculation of water flow by numerical methods and the representation of the solution by projecting the results of the numerical model onto the physical model, which creates a feeling of "virtual water". This is done in a rapid work cycle, which allows for the observation of solutions practically in real time. This way of working combines the accuracy and low cost of a numerical model with realistic immersion in the physical reality of the problem.

The basic idea is to extend the concept and performance of the well-known Augmented Reality SandBox (AR-SandBox) installations (Figure 1). The Augmented Reality Sandbox was developed 
by the UC Davis W.M. Keck Center for Active Visualization in the Earth Sciences (KeckCAVES, http://www.keckcaves.org), supported by the National Science Foundation, whose purpose is essentially didactic [17]. AR-SandBox presents simplified-equation models for the generation of virtual rain and runoff transformation on basin surfaces, as well as for water storage in reservoirs. It has the enormous advantage of providing instantaneous calculations and visual results, taking into account the variations in the basin topography. Conversely, it does not allow to the introduction or obtaining of any type of quantitative data, which makes AR-SandBox an essentially recreational and educational facility that does is not suitable for professional purposes.

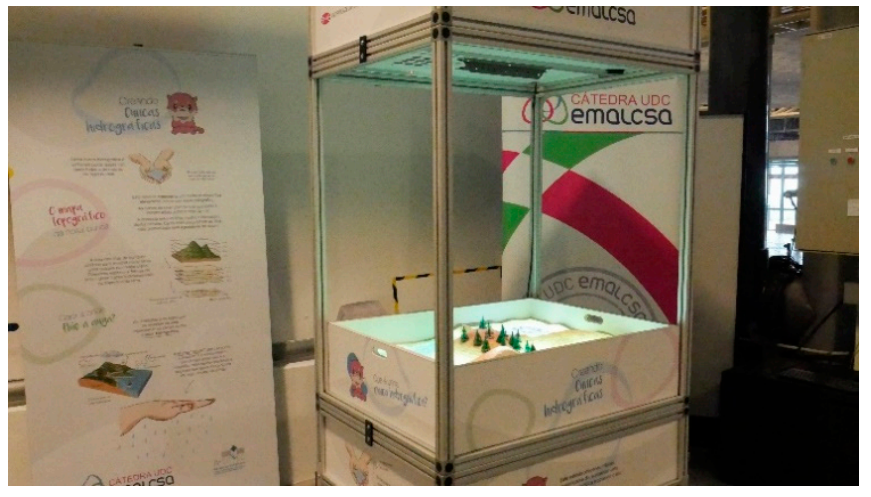

(a)

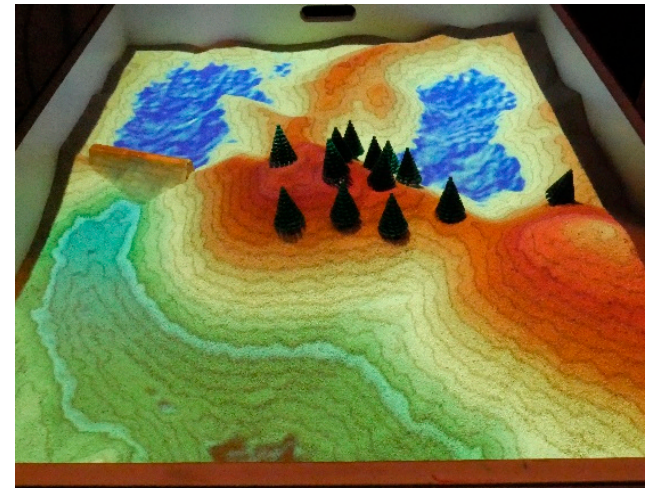

(b)

Figure 1. (a) General view of the Augmented Reality SandBox (AR-SandBox) module located in the Centre for Technological Innovation in Construction and Civil Engineering (CITEEC) facilities, and (b) detail of the topography projection on the sand.

Based on this idea, this work presents the development of a realistic simulator of flow in rivers and the analysis of flooding processes. This facility is called MEDUSA- 6 and its features include core software that manages the visualization and data acquisition, called TopoSandBox. This software is entirely original, coded from scratch using the Processing open-source graphical library [18]. It surpasses the AR-Sandbox capabilities by introducing sun lighting variations, shadows over the terrain, soil characterization by "virtually painting" parts of the physical model with textures, and other features now in development. Furthermore, the simulator has the advantage of working with quantitative technical data and solutions based on the river flow simulation software Iber that has been validated and used in many previous river inundation studies. Therefore, this work focuses especially on the integration of Iber simulations and results in the set of features that the system can currently display.

\section{Materials and Methods}

\subsection{Experimental Facility}

The installation presented in this paper is located in the Hydraulic Engineering Laboratory of the Center for Technological Innovation in Building and Civil Engineering (CITEEC) at the University of A. Coruña (Spain). The general purpose of the Hydraulic Engineering Laboratory is the analysis of urban water systems and water-sensitive urban developments (WSUD). This laboratory includes permanent facilities called WSUD Experimental Modules (or MEDUSA from its acronym in Spanish), with essentially research-based purposes, but also with educational and informative aims. These facilities cover different aspects of urban water systems, including supply, sanitation, drainage, surface water quality control, Sustainable Urban Drainage Systems (SUDS) and urban flooding (including pluvial and river flooding). It is in this latter area that the facility described in this work, also named MEDUSA-6, is framed. The basic work cycle in the MEDUSA-6 installation consists of: 
1. Building a geometry in the sandbox that represents the terrain to be modeled and incorporates the desired additional elements (buildings, dikes, etc.).

2. Extracting the digital elevation model (DEM) from the geometry. For this purpose, MEDUSA-6 includes as an element for topographic restitution a Kinect sensor, the same as the one used in the AR-SandBox installation. From the depth data of a set of points in the physical model, the TopoSandbox software, also developed by this team, obtains a DEM corresponding to the topography associated with the terrain that is being simulated, and calculates its characteristics such as contour lines, hypsometric curves, solar illumination or projected shadows (Figure 2).

3. Projecting contours, hypsometric curves or other data visualizations on the sandbox, to make visible the altimetry and detect possible calibration errors. Periodic calibration of the equipment is recommended and should be executed the first time the system is run.

4. Defining, through a simple interface, the spatial scales of the model, as well as the input hydrographs, the boundary and initial conditions, and the spatial discretization. This interface is accessible to any user, which allows the installation to be used for teaching purposes.

5. Running the two-dimensional river inundation model Iber+ (www.iberaula.com) directly from the interface.

6. Projecting the water depth results computed by the model onto the sandbox in real time, which makes it possible to observe the time evolution of the flow in the main channels, the flooding of low level areas, and the filling or emptying of controlled flood zones, for example.

7. Repeating the work cycle by varying the topography and geometry (by manipulating the sand or the objects placed in the sandbox) and/or the hydrographs and boundary conditions.

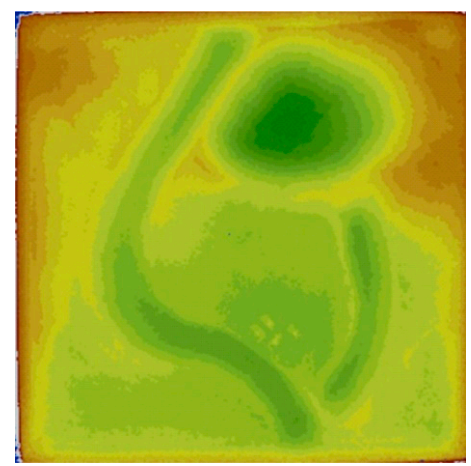

(a)

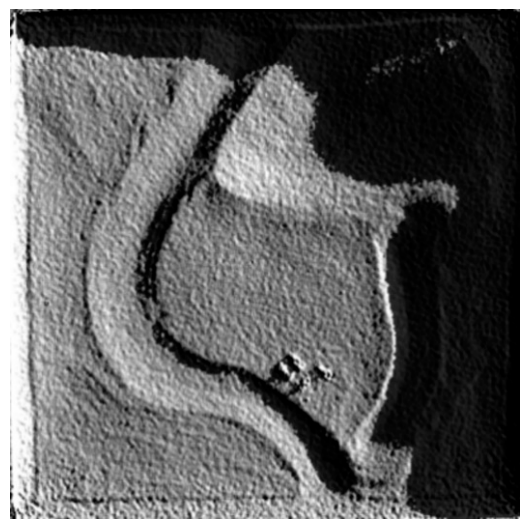

(c)

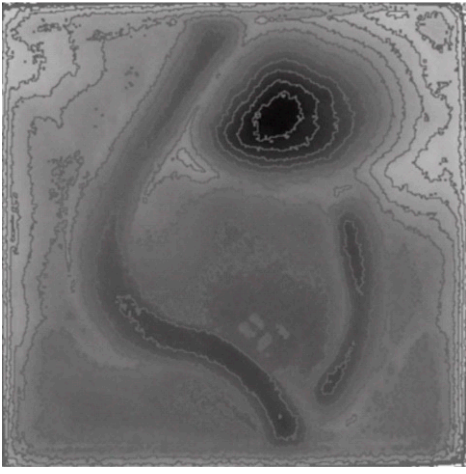

(b)

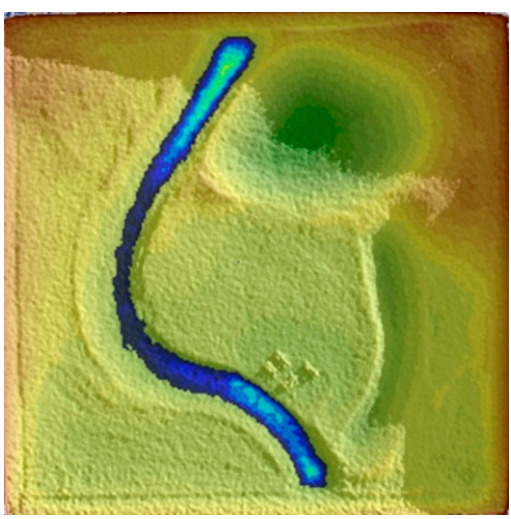

(d)

Figure 2. Graphic interface of the TopoSandBox software: (a) hypsometric, (b) depth map and contours, and (c) light/shadows modules. (d) Module combination and result visualization. 
The technical elements that allow above work cycle are shown in Figure 3:

1. A sandbox of $2.4 \times 2.4 \mathrm{~m}^{2}$. This is much larger than the usual standards for the AR-Sandbox, since the aim is to be able to implement relatively complex geometries, without reaching the precision of the physical models of the traditional hydraulic laboratories, yet with a relatively good degree of definition.

2. The sand bed has an average depth of $40 \mathrm{~cm}$, which allows the easy generation of river reaches, depressions and reservoir areas at various scales. The range of reasonable scales to represent in this installation is 100-1000, and it is possible to work with distorted scales in horizontal and vertical directions.

3. The sensors and cameras that allow us to obtain the height of the sand surface and objects placed in the sandbox, with which the digital model of elevations will be calculated. The installation is modular and allows the configuration of any element. Currently, we are working with a Kinect-2 module, which is placed $3.5 \mathrm{~m}$ above the average sand height. This module integrates a distance sensor (depth camera), thus making it possible to superimpose the DTM onto the image of the sandbox. The depth camera of the Kinect- 2 module works by sending a structured infrared light pattern of 34,749 points repeated $3 \times 3$ times over the scene. The scene is captured from a slightly offset point of view, obtaining the distance to the sensor by computing the parallax of each of the points. The resolution and precision of the position information will therefore be variable, since the density of points projected onto a surface will decrease with the distance of the sensor from it, both in horizontal and vertical aperture and in depth. In this installation, the horizontal and vertical resolution between measurements is $0.72 \mathrm{~cm}$ for an average distance of $3 \mathrm{~m}$. The resolution in depth is also variable, as we have noted. Although there are no manufacturer specifications, there are studies that indicate a depth resolution of $2.4 \mathrm{~cm}$ at a distance of $3 \mathrm{~m}$ [19]. However, the measurements taken in our installation give us a vertical resolution of $1.4 \mathrm{~cm}$, regarding the distance between the sand surface and the Kinect- 2 sensor. The projection onto the sandbox of the contours defined by the sensors, and the results of the model, are done by a conventional projector. The specific model in the MEDUSA-6 installation is the Vivitek DX281ST (Vivitek, The Netherlands) and was chosen for its projection surface and its luminosity at an accessible cost.

4. An opaque curtain for a more suitable projection space.

5. A control station where the software package TopoSandBox, registered at the University of A. Coruña, is installed. This software performs all operations related to the work cycle in a compact way, including the numerical simulation with the Iber software (which is also integrated into the system). In this way, all work develops with great simplicity and from a single interface, accessible to any type of user, thus allowing didactic or professional uses. A screen is available for the visualization of the model and for the projection of the results onto the sandbox itself.

6. The simulator is calibrated by projecting the computer screen displaying topographical features, such as contour lines, which are obtained from the depth data measurements of the Kinect-2 module. Then, a small calibration tool that is included in the TopoSandBox software allows translation and zooming of the projection until it matches the real world coordinates. Regular-shaped objects, easy to identify, should be placed on the sand to facilitate the procedure.

All the elements that make up MEDUSA-6 can be considered low-cost technology and all the software packages developed are open or free to use, so that anyone interested in reproducing the installation can do so at a very moderate cost and without paying for licenses.

Obviously, all the limitations that apply to conventional physical models, due to the choice of the Froude similarity criterion, or the scale effects linked to the viscosity or surface tension of the water, do not apply to this installation. However, limitations do arise due to the precision of the sensors that detect the elevations and the shadow effects that can be generated, for example, by a bridge over the riverbed. If we want to analyze the effect of the piles of a bridge, we can include them without any 
problem, but if the bridge deck is also included, the sensors will not see the river below and it will be identified as if it were a small dam. Such limitations must be taken into account, and mechanisms will probably be found to solve them in future versions of the installation.

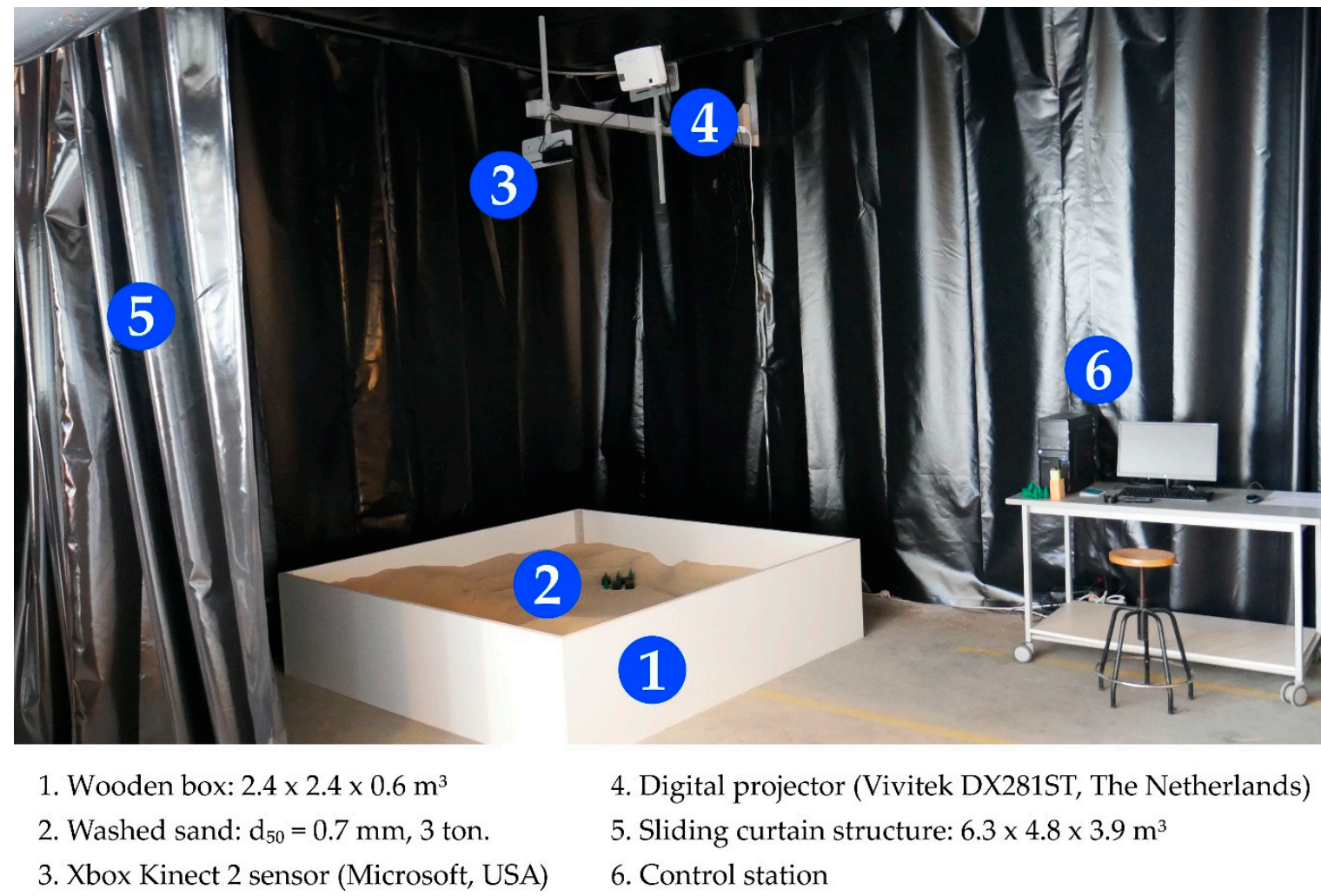

Figure 3. General view of the facility with the description of its main elements.

\subsection{Iber Numerical Model}

\subsubsection{Description of the Hydraulic Software}

Bearing in mind the previous requirements, MEDUSA-6 incorporates the freely available software Iber+ [20], a Graphics Processing Unit (GPU) parallelized version of the 2D hydraulic Iber model [21] for the simulation of water flow in rivers and open channels. Since the technical description of the mathematical model is beyond the scope of this paper, we will simply mention that it solves the two-dimensional shallow water equations over both structured and unstructured meshes using a finite volume approach. The shallow water equations are solved with a finite volume solver explicit in time, which implements Roe's scheme [22] for the discretization of the convective flux terms and an upwind discretization of the topography [23]. This gives the code a high degree of flexibility and robustness to model water flow over complex topographies and geometries at any spatial scale and resolution. Specific details relating to the mathematical implementation can be found in Bladé et al. [21] and the references therein.

The hydrodynamic equations solved by Iber constitute a high-fidelity physically-based mathematical model, and at the present time these are assumed to be the most efficient representation of inundation processes in rivers, which makes this software especially suitable for MEDUSA-6. The only parameter to be calibrated in the equations is the Manning coefficient, which is used to represent bed roughness and is usually related to land use. The Manning coefficient is widely used in hydraulic engineering problems, and thus plausible values for real applications can be established from any open channel flow or river engineering manual. 
Regarding its reliability, the software Iber has been widely applied to river inundation modelling in real-world cases [24-27], and it has been validated with field and laboratory data as well as analytical solutions in many previous studies [21,28-30].

The GPU parallelized version of the model (Iber+) decreases by two orders of magnitude the time required to perform a simulation, being able to produce results faster than real-time in real-world applications [20]. In fact, this software has recently been implemented in several flood early warning systems [31,32]. Thus, this high-speed computation makes Iber+ perfectly suitable for use in this facility.

An additional advantage of using Iber is that, although the model was originally developed for hydraulic computations of river flow, in recent years its range of applications has been expanded to the simulation of hydrological processes [33], water quality in rivers [34,35], urban drainage [36,37], soil erosion and sediment transport [38-40], fish habitat in rivers [41,42] and wood transport in rivers [43]. Thus, although the present version of MEDUSA-6 is only intended to simulate river flow, future versions could incorporate the ability to deal with hydrological simulations at the catchment scale and water quality simulations in rivers.

\subsubsection{Implementation in MEDUSA-6}

The measurement of the elevation map and its projection onto the sand is managed through a code developed with Processing 3.0 software. This is coding software developed by researchers at MIT [18] and is designed to facilitate the programming of audiovisual elements. One of the libraries included with this software makes it possible to obtain the point cloud measurement with the Xbox Kinect 2 sensor. The code developed for MEDUSA- 6 allows for the real time measurement and projection of the elevations according to the shapes drawn in the sand. Besides this module, the code includes more visualization functions, such as: (i) hypsometric, (ii) contours, and (iii) light \& shadows, but their description is beyond the scope of this work.

A function has been programmed to export an instantaneous height map of the sand shape. In addition, a script has been developed in Matlab to implement the calculation of the hydrological model with Iber+ in the exported topography. To do this, the first step is to replace the height measurements in the input file of Iber. Then, the $\mathrm{x}-, \mathrm{y}$ - and $\mathrm{z}$-coordinates are multiplied by a scale factor with the possibility of distorting the model, introducing a horizontal and a vertical scale. Moreover, the river baseflow can be established, and the study hydrograph is selected. Within the process of preparing the input data, a 'hot start' is considered so that steady flow conditions in the basin can be reached before the beginning of the hydrograph selected.

To simplify the TopoSandBox code, meshes with cell sizes ranging from 1 to $10 \mathrm{~cm}$ were pre-set, all of them structured, which allowed for quick visual analyses of the outcome differences regarding the spatial discretization (Figure 4). The mesh with the largest number of elements was built with a cell size of $1 \mathrm{~cm}$ (total 52,900 elements), as this was close to the resolution of the Xbox Kinect 2 inside the sand square $(335 \times 335$ pixels). Thus, this mesh setup allows us to model a flood event of $3 \mathrm{~h}$ in a river basin of $1.3 \mathrm{~km}^{2}$ in approximately 1 min of computational time (i.e., almost 200 times faster than real time), using a standard computer with a NVIDIA GeForce GTX $1050 \mathrm{Ti}$, a very affordable hardware configuration.

Once the simulation is performed, the output files obtained with Iber+ are loaded from the Processing code itself to project the result time series onto sand. Although the hydraulic software implementation in TopoSandBox code was performed for Iber+, it would be possible to develop a similar procedure to apply other hydraulic models. In the following section, the educational and training use of MEDUSA-6 will be discussed. In addition, it application to a case study will be described, in which a storm episode on a river basin and the use of flood protection systems are simulated. 

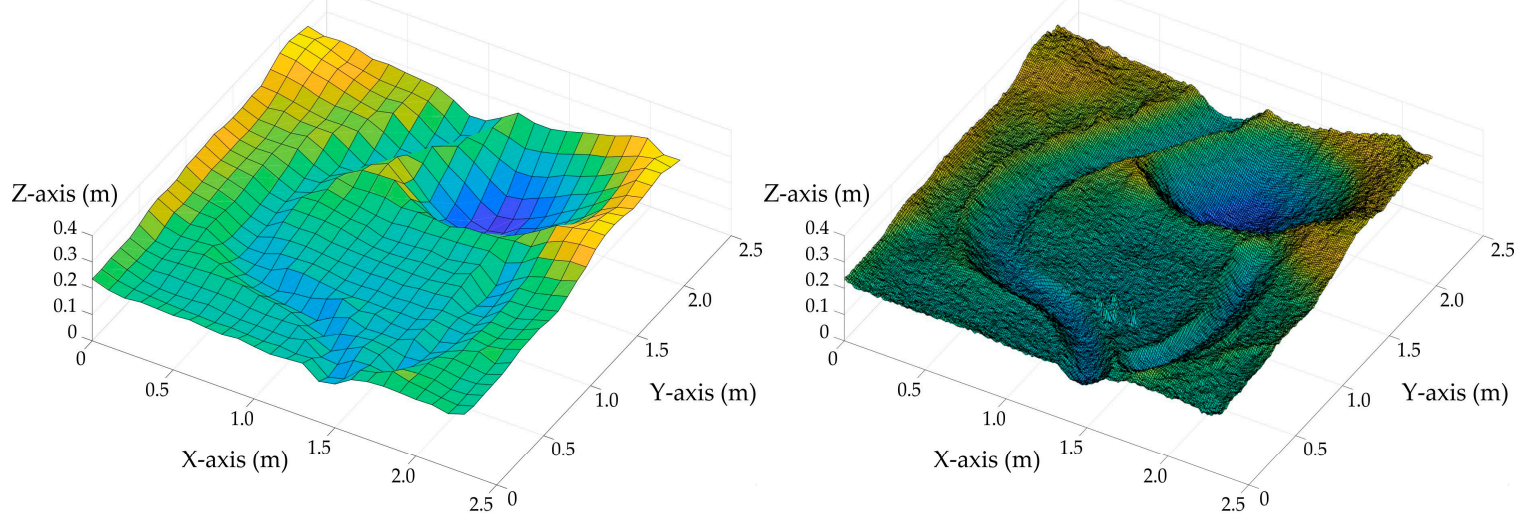

Sand elevations $(\mathrm{m})$

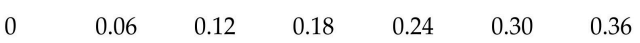

(a)

(b)

Figure 4. Representation of different mesh sizes. Cell size of (a) $10 \mathrm{~cm}$, and (b) $1 \mathrm{~cm}$.

\section{Use of the Installation and a Quantitative Example}

\subsection{Educational and Training Use}

The CITEEC is a research center that receives visits from hundreds of school-age children and young people. The proposed augmented reality facility has many educational possibilities. Beyond the field of hydraulic engineering, experimental tests are being designed for the reproduction in the sandbox of a topography delivered on a physical support, so that the colors of the projection indicate whether the terrain is above or below the target level, and also for the reproduction of architectural structures in their environment for the analysis of light and shadows.

With a young audience in mind, different teaching experiences can be easily designed, as for instance the visualization of rainfall-runoff transformation in a simple hydrological basin, which can be complemented with graphs of the different water balance components, or the effects of different flood protection measures in a river reach. Furthermore, the simulator can be configured to show the influence of parameters such as basin slope, permeability or the macro-roughness in the surface flow calculation, for instance, the differences in the time-flow distribution that would lead the permeability in urban and green areas, considering the infiltration processes and the temporary storage in permeable sub-layers [44]. Similar to the work of Viero and Valipour [45], the effect of the orientation of macro-roughness on the ground could be also highlighted for educational purposes.

In the professional field, the types of model that can be developed are similar. If we consider the example described in the following section, the visualization of the effect of a controlled flood zone as a measure for flood control (included in the Nature Based Solutions (NBS) block) for non-technical stakeholders on the MEDUSA-6 installation is highly illustrative, and the fact that the involved parties themselves can manipulate and directly evaluate the effect of the measures generates a stakeholder engagement effect that is difficult to achieve by other means.

Once a basic solution is outlined and modelled, the topography and the assets susceptible to being flooded can be delimited with the precision compatible with the limitations of the equipment, and quantitative solutions can be offered, at the same level as in any conventional physical or numerical model, using an auxiliary screen to project graphics or figures in real time, making MEDUSA-6 a professional facility with great potential. 


\subsection{Application to a Case Study}

One of the advantages of the MEDUSA- 6 is the possibility of carrying out a flood study in a river area/basin (Video S1). To do this, we need to reproduce the topography of the terrain in the physical model and to know the hydraulic conditions to perform a numerical simulation with the Iber+ model. The ease of modifying the topography and the speed of running simulations allow both the study of the consequences produced by adverse hydraulic phenomena, such as flooding caused by strong storm episodes, and the design and evaluation of mitigation strategies.

As an example, a river area has been reproduced in the sand (Figure 5a). This area is reproduced with a horizontal scale of 1:500 and a vertical scale of 1:250. Downstream, a population center has been located close to the river bank. The base flow of the river has been set at $100 \mathrm{~m}^{3} / \mathrm{s}$. In addition, a triangular hydrograph has been selected, which shows a peak flow of $1500 \mathrm{~m}^{3}$ at $0.5 \mathrm{~h}$ with respect to the beginning of the simulation and a total duration of $2 \mathrm{~h}$.

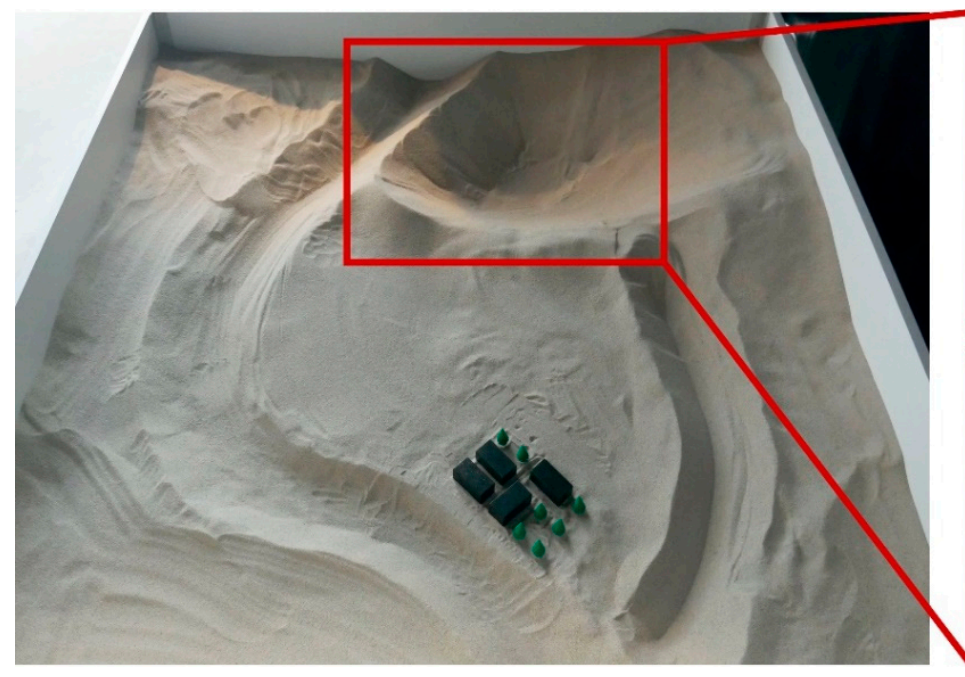

(a)

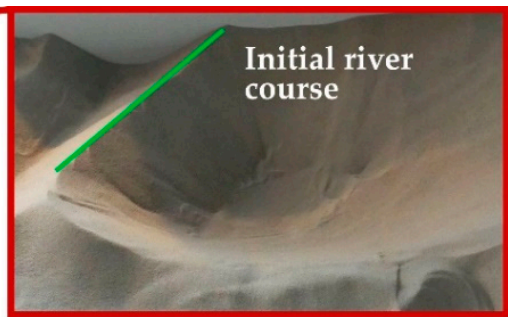

Modified river course

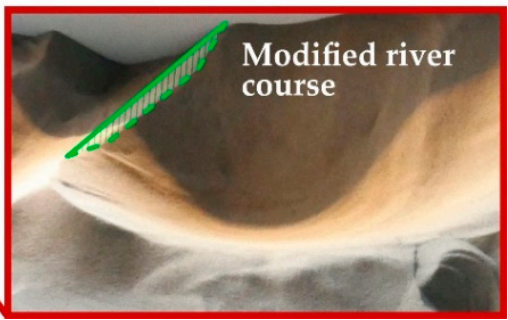

(b) \& (c)

Figure 5. (a) View of the river basin in the sand model; (b-up and c-down) differences between the two sand topographies analyzed.

The conditions established in this case study have resulted in the flooding of the urban area downstream of the basin, exceeding $2 \mathrm{~m}$ of water level in some places during the storm event (Figure 6a). There are differences in strategies for mitigating the effects of flooding. In this case study, the diversion of the stormwater flow to the flood protection reservoir was the strategy outlined. The simulations under this new configuration confirmed flood control, hence the population was not affected, avoiding possible material and personal damage (Figure $6 \mathrm{~b}$ ). In addition, Figure $6 c, d$ show the projection of the results on the sand at the same time under both hydraulic scenarios. This facilitates the visual localization of the area with the greatest potential risk of flooding and the decision-making process. As the simulator allows us to perform changes in the topography and re-simulate adverse hydraulic conditions, protection elements and strategies can be easily analyzed to establish the most efficient strategy and thus reduce the impact and associated cost of flooding. 
Flood

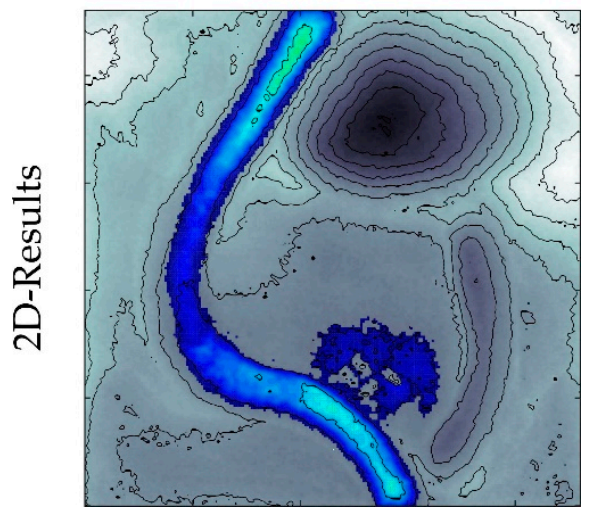

(a)

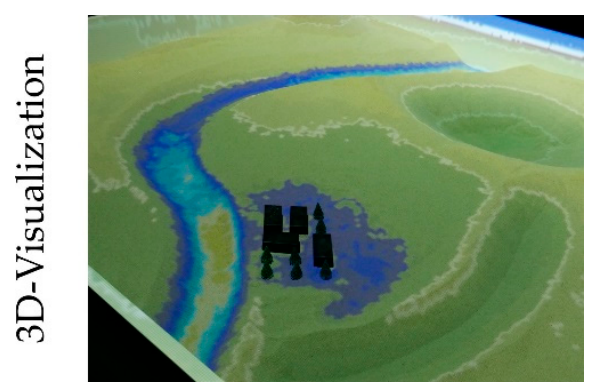

(c)
Anti-flood system

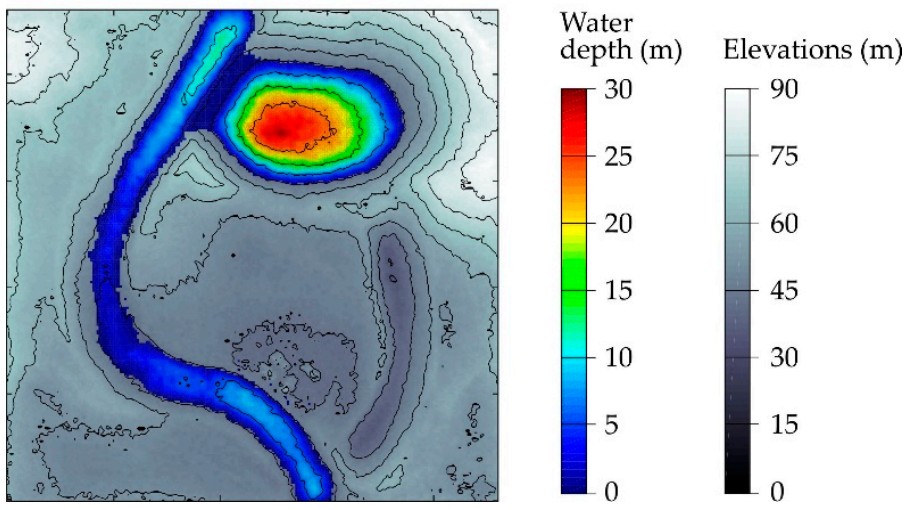

(b)

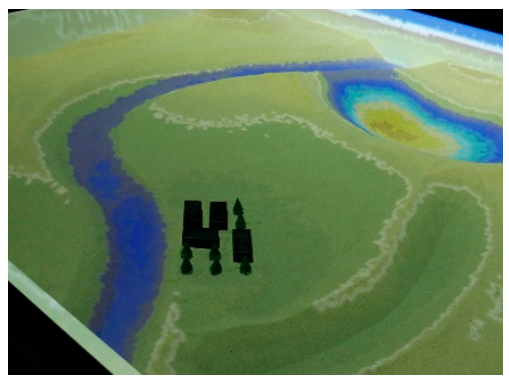

(d)

Figure 6. Elevation and water depth maps after $1 \mathrm{~h}$ from the beginning of the hydrograph under (a) flood and (b) anti-flood system conditions. (c,d) Detail of the projection of both results on the sand.

\section{Conclusions}

A physical-numerical hybrid facility (MEDUSA-6) has been developed for the modeling of water flow in river reaches. This article presents the installation and its application to river flooding, although the range of potential applications in the fields of hydraulic and hydrological engineering is huge.

The MEDUSA-6 facility is conceptually based on the same idea of the AR-SandBox module, but it introduces significant improvements related to the quantification of the water flow because of the implementation of the hydraulic simulation model Iber. All software has been developed from the outset. Thus, the digital elevation models can be accessed directly, and key variables such as rainfall, flow, levels and scales are perfectly quantifiable and exportable for simultaneous or subsequent use.

This shift towards a quantitative approach is the main contribution of the installation, one which, without abandoning its didactic potential, also has a great potential for professional use, and as a training tool in universities.

The physical installation of MEDUSA- 6 is low-cost. The total cost of the box, the uniform sand, the projector, the Kinect sensor and the control PC barely exceeds 2000 euros. The control software and the calculation model are free to use. We are working on a repository to facilitate access to the models and the basic indications for the installation of the equipment, so that any university or institution can, if they wish, reproduce the installation, without any limitations.

Supplementary Materials: The following supplementary video is available online at http://www.mdpi.com/20734441/12/11/3290/s1, Video S1: MEDUSA-6 presentation.

Author Contributions: The conceptualization of this study was made by J.P., L.H.-I., V.B.-N. and F.-A.V.-G.; the methodology applied in this research was developed by J.P., L.H.-I., L.C. and M.R.-P.; software development was carried out by L.H.-I., L.C. and M.R.-P., and its validation and formal analysis was performed by M.R.-P.; the investigation was conducted by J.P., L.H.-I., L.C. and M.R.-P.; resources were provided by J.P., L.H.-I. and L.C.; data curation was managed by M.R.-P.; writing-original draft preparation was written by J.P., L.H.-I., L.C., 
M.R.-P., V.B.-N. and F.-A.V.-G.; writing-review and editing, L.C., M.R.-P., V.B.-N. and F.-A.V.-G.; visualization material was prepared by M.R.-P.; supervision was carried out by J.P. and L.H.-I.; project administration was managed by J.P. and L.H.-I.; funding acquisition was obtained by J.P. and L.H.-I. All authors have read and agreed to the published version of the manuscript.

Funding: This research was funded by Agrupación Estratéxica CITEEC (A-CITEEC), grant number ED431E2018/11.

Acknowledgments: The A-CITEEC was supported by the grant for the improvement, creation, recognition and structuring of Strategic Consortiums in the Galician University System (Reference: ED431E/11) from the Consellería de Cultura, Educación e Ordenación Universitaria (Xunta de Galicia).

Conflicts of Interest: The authors declare no conflict of interest. The funders had no role in the design of the study; in the collection, analyses, or interpretation of data; in the writing of the manuscript, or in the decision to publish the results.

\section{References}

1. Mateos, C. La modelación física en las obras hidráulicas. Ing. Agua 2000, 7, 55-70. [CrossRef]

2. Moy de Vitry, M.; Dicht, S.; Leitão, J.P. floodX: Urban flash flood experiments monitored with conventional and alternative sensors. Earth Syst. Sci. Data 2017, 9, 657-666. [CrossRef]

3. Teng, J.; Jakeman, A.J.; Vaze, J.; Croke, B.F.; Dutta, D.; Kim, S. Flood inundation modelling: A review of methods, recent advances and uncertainty analysis. Environ. Model. Softw. 2017, 90, 201-216. [CrossRef]

4. Mignot, E.; Li, X.; Dewals, B. Experimental modelling of urban flooding: A review. J. Hydrol. 2019, 568, 334-342. [CrossRef]

5. Puertas, J.; Rabuñal, J. CITEEC. Catálogo de Proyectos de Investigación e Innovación Tecnológica 2000-2017, 1st ed.; Servizo de Publicacións Universidade da Coruña: A Coruña, Spain, 2017; p. 170, ISBN 978-84-9749-662-9. Available online: https://www.udc.es/citeec/documentos/catalogo_citeec.pdf (accessed on 29 September 2020).

6. Regueiro-Picallo, M.; Rojo-López, G.; Puertas, J. A-CITEEC: A strategic research consortium for R\&D\&I and transfer of results in civil engineering and building. Int. J. Sustain. High. Educ.. in press.

7. Li, W.; Nee, A.Y.C.; Ong, S.K. A state-of-the-art review of augmented reality in engineering analysis and simulation. Multimodal Technol. Interact. 2017, 1, 17. [CrossRef]

8. Art+Com. Terravision Project. 1994. Available online: https://artcom.de/en/project/terravision/ (accessed on 22 September 2020).

9. Hernandez-lbáñez, L.; Taibo, J.; Seoane, A. Una aplicación para la navegación en tiempo real sobre grandes modelos topográficos. In Proceedings of the CEIG, Jaen, Spain, 16-19 June 1999.

10. Omniglobe. Available online: https://arcscience.com/omniglobe-installations/ (accessed on 22 September 2020).

11. Hernandez-Ibañez, L.; Taibo, J.; Seoane, A.; López, R.; Jaspe, A.; Varela, A. Real-time visualization of geospatial features through integration of GIS with a realistic 3D terrain dynamic visualization system. In Proceedings of the XXII International Cartographic Conference (ICC2005), A Coruña, Spain, 9-16 July 2005.

12. Piper, B.; Ratti, C.; Ishii, H. Illuminating Clay: A 3-D Tangible Interface for Landscape Analysis. In Proceedings of the SIGCHI Conference on Human Factors in Computing Systems, Minneapolis, MN, USA, 20-25 April 2002; pp. 355-362.

13. iSandbox. Available online: https://ar-sandbox.com/ (accessed on 22 September 2020)

14. Priestnall, G.; Gardiner, J.; Durrant, J.; Goulding, J. Projection augmented relief models (PARM): Tangible displays for geographic information. In Proceedings of the Electronic Visualisation and the Arts (EVA 2012), London, UK, 10-12 July 2012; pp. 180-187. [CrossRef]

15. Reed, S.; Kreylos, O.; Hsi, S.; Kellogg, L.; Schladow, G.; Yikilmaz, M.B.; Segale, H.; Silverman, J.; Yalowitz, S.; Sato, E. Shaping Watersheds Exhibit: An Interactive, Augmented Reality Sandbox for Advancing Earth Science Education. In Proceedings of the American Geophysical Union Fall Meeting 2014, San Francisco, CA, USA, 15-19 December 2014. ED34A-01.

16. ARSandbox. Available online: https://arsandbox.ucdavis.edu/ (accessed on 22 September 2020).

17. Kreylos, O.; Kellogg, L.H.; Reed, S.; Hsi, S.; Yikilmaz, M.B.; Schladow, G.; Segale, H.; Chan, L. The AR Sandbox: Augmented Reality in Geoscience Education. In Proceedings of the American Geophysical Union Fall Meeting 2016, San Francisco, CA, USA, 12-16 December 2016. ED51H-0843. 
18. Reas, C.; Fry, B. Processing: A Programming Handbook for Visual Designers and Artists, 2nd ed.; The MIT Press: Cambridge, MA, USA, 2014; p. 672.

19. Khoshelham, K.; Elberink, S.O. Accuracy and Resolution of Kinect Depth Data for Indoor Mapping Applications. Sensors 2012, 12, 1437-1454. [CrossRef]

20. García-Feal, O.; González-Cao, J.; Gómez-Gesteira, M.; Cea, L.; Domínguez, J.M.; Formella, A. An accelerated tool for flood modelling based on Iber. Water 2018, 10, 1459. [CrossRef]

21. Bladé, E.; Cea, L.; Corestein, G.; Escolano, E.; Puertas, J.; Vázquez-Cendón, M.E.; Dolz, J.; Coll, A. Iber: Herramienta de simulación numérica del flujo en ríos. Rev. Int. Métodos Numéricos Cálculo Diseño Ing. 2014, 30, 1-10. [CrossRef]

22. Roe, P.L. Discrete models for the numerical analysis of time-dependent multidimensional gas dynamics. J. Comput. Phys. 1986, 63, 458-476. [CrossRef]

23. Bermúdez, A.; Dervieux, A.; Desideri, J.A.; Vázquez-Cendón, M.E. Upwind schemes for the two-dimensional shallow water equations with variable depth using unstructured meshes. Comput. Methods Appl. Mech. Eng. 1998, 155, 49-72. [CrossRef]

24. Garrote, J.; Alvarenga, F.M.; Díez-Herrero, A. Quantification of flash flood economic risk using ultra-detailed stage-damage functions and 2-D hydraulic models. J. Hydrol. 2016, 541, 611-625. [CrossRef]

25. Bermúdez, M.; Neal, J.C.; Bates, P.D.; Coxon, G.; Freer, J.E.; Cea, L.; Puertas, J. Quantifying local rainfall dynamics and uncertain boundary conditions into a nested regional-local flood modelling system. Water Resour. Res. 2017, 53, 2770-2785. [CrossRef]

26. Sopelana, J.; Cea, L.; Ruano, S. A continuous simulation approach for the estimation of extreme flood inundation in coastal river reaches affected by meso and macro tides. Nat. Hazards 2018, 93, 1337-1358. [CrossRef]

27. Areu-Rangel, O.S.; Cea, L.; Bonasia, R.; Espinosa-Echavarria, V.J. Impact of Urban Growth and Changes in Land Use on River Flood Hazard in Villahermosa, Tabasco (Mexico). Water 2019, 11, 304. [CrossRef]

28. Cea, L.; Bladé, E.; Sanz-Ramos, M.; Fraga, I.; Sañudo, E.; García-Feal, O.; Gómez-Gesteira, M.; González-Cao, J. Benchmarking of the Iber Capabilities for 2D Free Surface Flow Modelling; Servizo de Publicacións Universidade da Coruña: A Coruña, Spain, 2020; ISBN 978-84-9749-764-0. Available online: http://hdl.handle.net/2183/24588 (accessed on 29 September 2020).

29. Fraga, I.; Cea, L.; Puertas, J. Validation of a 1D-2D dual drainage model under unsteady part-full and surcharged sewer conditions. Urban Water J. 2017, 14, 74-84. [CrossRef]

30. Sanz-Ramos, M.; Amengual, A.; Bladé, E.; Romero, R.; Roux, H. Flood forecasting using a coupled Hydrological and Hydraulic Model (based on FVM) and high resolution Meteorological Model. In Proceedings of the E3S Web of Conferences, Volume 40 (2018), River Flow 2018-Ninth International Conference on Fluvial Hydraulics, Lyon-Villeurbanne, France, 5-8 September 2018; pp. 1-8. [CrossRef]

31. Fraga, I.; Cea, L.; Puertas, J. MERLIN: A flood hazard forecasting system for coastal river reaches. Nat. Hazards 2020, 100, 1171-1193. [CrossRef]

32. Fernández-Nóvoa, D.; García-Feal, O.; González-Cao, J.; de Gonzalo, C.; Rodríguez-Suárez, J.A.; Ruiz del Portal, C.; Gómez-Gesteira, M. MIDAS: A New Integrated Flood Early Warning System for the Miño River. Water 2020, 12, 2319. [CrossRef]

33. Cea, L.; Blade, E. A simple and efficient unstructured finite volume scheme for solving the shallow water equations in overland flow applications. Water Resour. Res. 2015, 51, 5464-5486. [CrossRef]

34. Cea, L.; Bermúdez, M.; Puertas, J.; Bladé, E.; Corestein, G.; Escolano, E.; Conde, A.; Bockelmann-Evans, B.; Ahmadian, R. IberWQ-New simulation tool for 2D water quality modelling in rivers and shallow estuaries. J. Hydroinform. 2016, 18, 816-830. [CrossRef]

35. García-Feal, O.; Cea, L.; González-Cao, J.; Domínguez, J.M.; Gómez-Gesteira, M. IberWQ: A GPU Accelerated Tool for 2D Water Quality Modeling in Rivers and Estuaries. Water 2020, 12, 413. [CrossRef]

36. Cea, L.; Garrido, M.; Puertas, J.; Jácome, A.; del Río, H.; Suárez, J. Overland flow computations in urban and industrial catchments from direct precipitation data using a two-dimensional shallow water model. Water Sci. Technol. 2010, 62, 1998-2008. [CrossRef] [PubMed]

37. Fraga, I.; Cea, L.; Puertas, J.; Suárez, J.; Jiménez, V.; Jácome, A. Global sensitivity and GLUE-based uncertainty analysis of a 2D-1D dual urban drainage model. J. Hydrol. Eng. 2016, 21, 04016004. [CrossRef] 
38. Bladé, E.; Sánchez-Juny, M.; Arbat-Bofill, M.; Dolz, J. Computational modelling of fine sediment relocation within a dam reservoir by means of artificial flood generation in a reservoir cascade. Water Resour. Res. 2019, 55, 3156-3170. [CrossRef]

39. Cea, L.; Legout, C.; Grangeon, T.; Nord, G. Impact of model simplifications on soil erosion predictions: Application of the GLUE methodology to a distributed event-based model at the hillslope scale. Hydrol. Process. 2016, 30, 1096-1113. [CrossRef]

40. Naves, J.; Rieckermann, J.; Cea, L.; Puertas, J.; Anta, J. Global and local sensitivity analysis to improve the understanding of physically-based urban wash-off models from high-resolution laboratory experiments. Sci. Total Environ. 2020, 709, 136152. [CrossRef]

41. Bladé, E.; Sanz-Ramos, M.; Vericat, D.; Palau-Ibars, A. New Tools to Assess the Suitability of Physical Habitat (SPH) and the Weighted Usable Area (WUA) for Fishes. In Advances in Hydroinformatics; Gourbesville, P., Caignaert, G., Eds.; Springer: Singapore, 2020; pp. 735-743. [CrossRef]

42. Sanz-Ramos, M.; Bladé Castellet, E.; Palau Ibars, A.; Vericat Querol, D.; Ramos-Fuertes, A. IberHABITAT: Evaluación de la Idoneidad del Hábitat Físico y del Hábitat Potencial Útil para peces. Aplicación en el río Eume. Ribagua 2019, 6, 158-167. [CrossRef]

43. Ruiz-Villanueva, V.; Bladé, E.; Sánchez-Juny, M.; Marti-Cardona, B.; Díez-Herrero, A.; Bodoque, J.M. Two-dimensional numerical modeling of wood transport. J. Hydroinform. 2014, 16, 1077. [CrossRef]

44. Viero, D.P.; Peruzzo, P.; Carniello, L.; Defina, A. Integrated mathematical modeling of hydrological and hydrodynamic response to rainfall events in rural lowland catchments. Water Resour. Res. 2014, 50, 5941-5957. [CrossRef]

45. Viero, D.P.; Valipour, M. Modeling anisotropy in free-surface overland and shallow inundation flows. Adv. Water Resour. 2017, 104, 1-14. [CrossRef]

Publisher's Note: MDPI stays neutral with regard to jurisdictional claims in published maps and institutional affiliations. 